\title{
Followership in Higher Education: Academic Teachers and their Formal Leaders
}

\section{ABSTRACT}

The concept of followership in higher education has been given limited attention despite the fact that followers are key players in the follower/leader equation and that leadership is increasingly seen as vital to improving the student learning experience. This paper explores this concept, reporting on the findings of a qualitative study underpinned by a socio-constructivist framework. Thirtyeight narratives describing the experience of being a follower and interacting with a formal leader were collected from academic teachers in seven institutions worldwide and analysed using inductive content analysis. The richness of the narratives collected illustrates the intricate relationship formed by the followership/ leadership interaction. The results affirm the premise that, just as teachers are defined by their students'learning, leaders are defined by their followers' engagement. However, some teachers also display a strong reluctance towards the very idea of being a follower in academia where critical and independent thinking form the backbone of all practices. Negotiation, responsibility, and mutual respect appear essential aspects of any form of followership/leadership interaction as it directly or indirectly influences student learning and personal development. The research presented suggests that, in challenging times, academic leaders must attend to the characteristics and needs of their followers.

\section{KEYWORDS}

followership, academic leadership, narratives, relational spaces

A plethora of changes in higher education over the last 20 years (Jones, Lefoe, Harvey, \& Ryland, 2012) has created challenges for academic leaders. Much research has addressed these leadership challenges, but the work has been dominated by a focus on the role and significance of the formal leader (Cox, Plagens, \& Sylla, 2010). In this paper, we contribute to the literature on academic leadership by focusing on the complex relationship between follower and leader in the realm of teaching and learning in higher education. Responding to Alvesson and Spicer's (2011) recommendations, we explore followership, claiming that followers define leaders, since without followers, leadership is meaningless. 
Most of the research literature focuses on "formal" leadership positions in organisations and, although studies that examine leadership in teaching and learning do exist, they are in the minority (Marshall, Orrell, Cameron, Bosanquet, \& Thomas, 2011; Martin, Trigwell, Prosser, \& Ramsden, 2003). Even fewer works include accounts of academics' experiences of "being led." Recognition of the need for additional research in this area stimulated a project in which we examined how academic teachers perceive and make sense of teaching and learning situations where they interact with leaders. While we acknowledge that there are multiple forms and types of leadership, including those more informal and less visible, in our study we focus on followers' experiences with formal (appointed) leaders.

Our results were illuminating. While we identified themes relating to differing leadership behaviors and styles, as well as teacher reactions to leadership practices, more significantly, we collectively recognized the importance of the relational space between follower and leader. Similar to Carsten, Uhl-Bien, West, Patera, and McGregor (2010), we found that, rather than the follower being viewed simply as a subordinate, there is a continuum of followership, moving from being an acquiescent follower through to being a co-constructor of leadership. This paper focuses on the complex and shifting interactions, roles, and relationships between followers and leaders in teaching in higher education.

First, we provide an outline of the literature that supports our findings and situates our research within the fields of leadership in higher education specifically, and followership more generally. Next we identify social constructivism as our theoretical framework, narrative inquiry as our methodology, and content analysis as our analytical approach. We introduce our participants and discuss the positive and negative relational space between followers and leaders and its potential impact on teaching and learning. Our discussion illustrates how the data led to our argument, underscores its significance for teaching and learning, and recognizes that followership is not reactive but interactive, for indeed "organizational success is in the hands of followers" (Cox et al., 2010, p. 37). Finally, we identify recommendations for future research in the scholarship of leadership of teaching and learning.

\section{DEFINING OUR TERMS AND POSITIONING OUR RESEARCH}

We claim that the academic followership/leadership relationship is co-constructed, and in this paper we refer to followership, to balance out the prior emphasis on leadership in research studies focusing on leadership styles, behaviors, and skills (e.g., Allan, Gordon, \& Iverson, 2006; Gibbs, Knapper, \& Picinnin, 2009). Over time, that perspective has widened to include accounts of informal leadership (Kezar \& Lester, 2011), shared leadership (Weaver, Pifer, \& Colbeck, 2009), distributed leadership (Gosling, Bolden, \& Petrov, 2009), and the need to build leadership capacity and effectiveness (e.g., Jones et al., 2012). We concur with Alvesson and Spicer (2011), who suggest that these approaches leave us with an overemphasis on the leader and an oversimplified conception of the interactive processes in leadership. They advocate for research that acknowledges the messiness of leadership processes, and most of all, for the inclusion of followers and their perceptions of situations where leadership is in play. However, when followers' experiences have been considered, it has most often been as an afterthought in an examination of leadership (see Cox et al., 2010). The followership studies that do exist tend to fall into three areas, as Bjugstad, Thach, Thompson, and Morris (2006) indicate: studies that 
examine follower motivations, studies that look at follower trust and values, and studies that identify the traits of "good" or "bad" followers. Our investigation offers a newer perspective on followership by drawing on international data to identify how followership is experienced in relation to leadership.

Championing the role of the follower has its challenges, for the term itself retains "connotations of subordination, submission, passivity, and lack of control" (Bligh, 2011, p. 433). The term follower could suggest a simple, mechanistic process in which a leader does something and the followers react. Bjugstad et al. (2006) also acknowledge the troublesome nature of the term follower, identifying the dangers inherent in the tendency to reject the role, arguing that leaders can only succeed by permission of their followers. This reluctance to identify themselves as followers may explain why some of those asked to participate in our study refused to do so. Academic followers may also see themselves as informal leaders within teaching and learning, having power to influence others not through a formal process of appointment, but through credibility, experience, and other identifiers. Owing to the nature of academic work, an individual may be both a follower and a leader at different moments and in different situations. All of these factors make the term itself a contentious one in academic contexts.

Recognizing these challenges, we use the term followership to emphasize the skills, qualities, character, and power of the person doing the following, rather than merely the fact that he/she follows, since these characteristics are, or could be, shared in a meaningful, even purposeful way with others. Followership implies an active choice accompanied by engagement and responsibility, while follower implies a reactive stance, sometimes accompanied by withdrawal (Cox et al., 2010). Aware of the critique of leadership research (Alvesson \& Spicer, 2011), we recognize that all individuals involved are engaged in and share a social setting, where each individual has some level of agency, even if the leader stands out because of his or her title and control of resources. These elements of agency are encompassed within our use of the term followership.

Although agency is positioned within specific contexts, little research focuses on followership in the particular context of institutions of higher learning, and more specifically on teaching and learning, a context that we argue has historical, motivational, and organizational features that are unlike the business, engineering, or medical contexts in which followership has been predominantly studied (see Kean \& Haycock-Stuart 2011, for example). Nevertheless, academics appreciate good leaders (Martin et al., 2003; Ramsden, Prosser, Trigwell, \& Martin, 2007; Trevelyan, 2001) as much as they resent poor leadership, the latter causing both monetary and collegial costs, through institutions worldwide (Roxå \& Mårtensson, in press). These factors are relevant during a period in which performance and accountability within institutions are emphasised within an environment increasingly dominated by managerialism and bureaucracy (Billot \& Codling, 2013). In this paper, we identify how followers perceive themselves in relation to academic leaders, attending to the shifting nature of that relationship; we refer to the differing influences of context (systemic, organisational, and department-based) on those relationships, and we discuss how followers' constructions of the followership/leadership potentially affect teaching and learning.

The theoretical perspective adopted here is social-constructivism (Berger \& Luckmann, 1966), that sees people constructing the situation at hand and interpreting its meanings simultaneously. We acknowledge that all parties in the interaction are active 
and consequently share responsibility for its construction and outcome, even though one individual (officially appointed) has more formal resources at his or her disposal. Hence we are not looking for an absolute definition of followership, but rather we seek to understand how it comes into play in specific situations related to teaching and learning, and foremost, how it affects an individual's agency (Giddens, 2004) and perception of self.

We build on the work of Cox et al. (2010), who make a distinction between being a follower and being engaged in followership: "following is reactive ... followership is an a priori choice" (p. 48). Moreover, in the follower/leader relationship, both parties contribute interactively to the outcome. This resonates both with Berlin's (2000) reflection on negative and positive freedom and with the consequent implications of caution, negotiation, and mutual influence, as well as with Åkerlind and Kayrooz's (2003) research on academics' conceptions of academic freedom, and its emphasis on responsibility. It is, however, possible for followers to be disengaged or resistant, implying a potential negative emotional and monetary cost for an organization. Therefore, we claim that active, responsible followership is crucial to any organisation and its leaders' abilities to influence the teaching and learning domain.

Another important premise within our research is that the leadership/followership dynamic can have an important (if indirect) influence on student learning. Based on a survey of 439 Australian academics, Ramsden et al. (2007) conclude that "the practices of academic managers, and in particular heads of departments, are critical to the development of a collegial commitment to student learning” (p. 153). This research argues that a collaborative, open and empowering departmental leadership is linked to studentfocused teaching and furthers an increase in a deep approach to learning among students. Furthermore, the follower/leader dynamic is in many ways analogous to the student/ teacher relationship; just as the quality of students' learning defines the quality of teaching (Biggs \& Tang, 2007), followership defines the quality of leadership. Exploring the experience of followers, then, is a vital contribution to the discussion about leadership in higher education and its effect on student learning.

\section{METHODOLOGY AND ANALYTICAL APPROACH}

Since this project seeks to explore how academic teachers in higher education perceive and make sense of situations of followership, and given the premise that the experience of the individual is socially constructed (Carsten et al., 2010), we selected a qualitative approach to investigating the phenomenon of followership. Thus we were able to "study things in their natural settings attempting to make sense of, or interpret, phenomena in terms of the meanings people bring to them" (Denzin \& Lincoln, 2003, p. 5).

Narrative inquiry, within the context of qualitative methodology, is particularly appropriate in researching how people make sense of their lives by selecting and arranging information about noteworthy episodes (Cousin, 2009). Narratives "not only pass on information" but they also assist to "crystallize or define an issue, view, stance or perspective" (Cohen, Manion, \& Morrison, 2011, p. 553). More than mere data, narratives package experience as stories with an attached personal meaning (Webster \& Mertova, 2007). Since we are looking for the lived experience of working with educational leaders, we chose to collect narratives, as they allow us to look both at what stories the participants choose to tell and how they choose to tell them.

To gather these stories, we invited academics in teaching roles across the seven uni- 
versities where we work to write a narrative or participate in an interview that explored a teaching and learning situation in which they interacted with a formal leader. The leader was defined as "any person who has the power and resources to affect the teaching mission of the programme: these could include programme leaders/coordinators, heads of departments/schools, or senior administrators (e.g., deans)." There were no parameters placed on the narrative's length, structure, or type of experience described; however, we did provide the following prompts in order to offer some guidance:

-What was the context?

- What happened?

- How did people involved react; what did they say, do?

-What did you think about the situation at the time?

- What do you think now?

- When you reflect back upon your encounter with this particular leader, what did the encounter feel like? (You may perhaps wish to express this feeling in terms of a metaphor).

We chose this method to align with narrative inquiry premises whereby participants tell the story in their own way, basing it on an experience that was meaningful to them. When participants chose to undertake an interview, transcripts were produced and verified with the participant. Appropriate ethical clearance procedures were undertaken depending upon the requirements of each institution. Thirty-eight narratives were collected with representation from North America, Europe, and Australasia, and from numerous academic faculties including Education, Applied Health Sciences, Engineering, the Humanities, Sciences, and the Social Sciences.

A content analysis of the stories was undertaken using a recursive approach. Carsten et al. (2010) refer to this as "inductive analysis," in which researchers continually create and refine data to explain what is happening. To apply this analysis strategy, three of the researchers initially coded three narratives to form and refine a coding schema by identifying particular wording and definitions of the schema. The coding schema focused on the follower, leader, metaphors, lessons learned about the follower/leader interactions, and physical and relational contexts. Each of the remaining 35 narratives was analysed using the above schema by two researchers. In order to maintain the integrity of the data analysis process, researchers did not code any of the narratives that they themselves had collected. This method led to the identification of three themes that are reported in this paper. An additional source of data was provided by some non-participants in the form of unsolicited feedback as to the reasons why they did not want to participate in the study. These responses offer an important alternative perspective on the data that might otherwise have been missed.

\section{FINDINGS}

What follows is a concise overview of the main findings that emerged from our inductive analysis of the narratives. The narratives ranged in length from a single paragraph to six type-written pages. Sixteen of the 38 narratives we received were considered to be positive, 20 were negative, and 2 were neutral. How participants told their stories, as captured in the tone, emotional expressions, and metaphors (when used), formed the basis 
upon which we assigned each narrative to a particular category. Thus, if followers expressed that they were heard, treated fairly, respected, and recognized for their contributions to student learning or to the organization, we categorized the narrative as "positive." Alternatively, if they expressed unhappiness at being ignored, bullied, misunderstood, and/ or victimized, we categorized the narrative as "negative." If the story was mainly 'factual' with no strongly expressed positive or aversive outcomes, we considered the narrative to be "neutral." Our key findings are discussed below to give a clearer picture of how the follower/leader relationship in higher education may have implications for effective academic teaching work.

We begin by describing how our participants saw themselves both as teachers and as "followers." Their self-understandings were closely connected not only to their expectations and perceptions of leaders, but also to their implicit beliefs about the nature of teaching and learning, which shaped the way they responded to the scenario described in their narratives. Followers most often prided themselves on being principled and ethical teachers. Many individuals reported using "student-centered" teaching approaches and showed concern for the quality of students' learning. One academic captured the essence of the expressed views on teaching and learning thus: "We had worked for several years to set up an educational environment in which it was safe to be risky and risky to be safe ... a permissive environment where we want students to feel empowered." Followers viewed themselves also as the guardians of academic integrity and the facilitators of student motivation. As another academic put it, "one of the key learning and teaching considerations needs to be-how can learning and teaching be made congruent with what our students will need to succeed?"

With $42 \%$ of the narratives being positive and 52\% being negative (and the latter being far more vivid in choice of metaphors), we wondered why participants were choosing to tell more negatively framed stories rather than positively framed stories. To answer this question, we delved into the nature of the narratives and discovered that they reflected a continuum of positive to negative relational space. Uhl-Bien (2006) offers a framework known as Relational Leadership Theory (RLT) that views leadership as a process of social construction. Relationships are seen as a context for action. We frame this as the "middle space" between the follower and the leader, as seen from followers' perspectives. This invisible yet crucial "relational space" is thus the focus of our analysis. Using this analytic lens enabled us to (a) unearth some complexities of followership/leadership interactions that are particular to higher education settings, and (b) offer important implications for academics' teaching and learning work.

\section{FOLLOWERS AND LEADERS: CO-CONSTRUCTING POSITIVE RELATIONAL SPACES}

Positive relational spaces appeared to be cultivated when followers and leaders coconstructed optimal and healthy interactions and practices in workplace environments. These positive spaces were reported to empower, build confidence, and motivate followers to work hard. In the context of our study, followers' identity constructions were varied, complex, even fluid. They saw themselves shifting and changing through encounters with leaders throughout their career stages. Followers also recognized themselves as leaders in their own teaching and learning contexts, paving the way forward as innovators, de- 
velopers, collaborators, volunteers, negotiators, advocates, defenders, and change agents. They described valuing justice and integrity within academia and within their classrooms. Consequently, followers were especially grateful when their leaders' behaviors illustrated "genuine concern" for them as teachers or as mentors willing to take junior academics "through a step by step process" to foster good teaching.

In many of these narratives, followers remembered and recounted vivid experiences of interactions that influenced and supported their careers. Reports focused on workplace cultures where they experienced a sense of belonging, respect, and trust among colleagues, as well as encounters with leaders that encouraged a collective vision, the sharing of resources, and multiple opportunities for mutual support and collaboration. Other narratives suggested that empathy as well as fairness in recognitions, rewards, and responsibilities positively enhanced the teaching and learning environment.

In addition to positive relational space that promotes dialogue, negotiation and reflection, cultivating productive follower/leader relationships and interactions also requires clearly defined roles, responsibilities, and timelines. Timely, detailed, and balanced feedback from leaders further supported followers' growth as individuals, scholars, and teachers. Strong relationships between followers and leaders were more likely to be built on the sense of reciprocity, generous support, and community. Positive dynamics between followers and their leaders created environments that were flexible, open, trustful, and honest. Followers felt validated and sustained by respectful, empathetic, and encouraging interactions that fostered "exuberance and pride" and allowed them to "contribute in meaningful ways." The followers in our study expressed a desire to play active, positive roles and when they receive support, become strongly committed to doing significant teaching-related work.

Metaphors such as "on the right track" or a leader's "desire to grow another professor" were used to illustrate positive feelings about the follower/leader interactions. Leaders who relinquished more traditional (or narrower) conceptualizations of leadership enabled followers to enact new directions in teaching and learning, particularly if followers themselves were acknowledged and treated as "experts" by the wider community. Moreover, collaboration across differences was made possible when followers and leaders were focused on the shared goal of keeping students' needs and best interests at the core of their teaching and learning work.

\section{FOLLOWERS AND LEADERS: NEGOTIATING NEGATIVE RELATIONAL SPACES}

On the other hand, negative relational spaces occur when followers and leaders set up inhibiting, unhealthy, and damaging interactions or practices in their work environments. These negative relational spaces disempowered, bred cynicism, and had adverse psychological or emotional effects on followers. Negative narratives cited inadequate institutional or departmental structures, budgets and funding, or undesirable changes in course curricula and teaching standards. Rules and regulations, and ensuing or existing power relations that emerged from organizational processes were additional structural and psychological factors reported in negative tones. Thus, followers were distressed over leaders' negative behaviors that resulted in creating a "closed and competitive" atmosphere with people being "strategically excluded ... without any consideration for the damage 
being done to relationships." Furthermore, when followers' own self-understandings did not align with the perception their leaders had of them, they expressed strong feelings of tension, isolation, and vulnerability. As one academic recalled, "the lonely dread of being perceived as a 'stirrer,' the very real fear of emotional and professional exile, I felt them all keenly; I was miserable, and I struggled."

Followers reported differing levels of agency. A follower's or leader's action (or lack thereof) also appeared to reflect the larger institutional culture where leadership might be viewed as more (or less) challengeable. Thus, a follower said that she saw herself as asking a prison guard for "extra time in the yard," and another individual reported feeling that she had to struggle to "break free from the isolated cocoon" of a dysfunctional department. It seems reasonable, then, to conclude that both psychological and physiological factors embedded in the follower/leader interaction would affect the quality of the teaching and learning environment.

Followers chose different strategies to deal with criticism by leaders. "Passive" action, for example, involved staying silent, acting agreeable, or distancing themselves, conforming, or individually struggling to cope in changing and challenging circumstances. Although some followers chose not to react immediately, they sometimes reframed negative encounters by preferring to stay focused on improving their teaching practice, or affirming personal professional values. Others reported more active responses such as critically questioning the situation, other people's and their own behaviors, either publicly or in internal dialogues. When engaging in disempowering or frustrating interactions with leaders, some followers reported spiteful, accusatory, and revengeful practices (even if later they regretted the behavior) or risk-taking, resisting, and forming allegiances to stand their ground.

Followers' narratives sometimes problematized the ways in which power and politics play out between people, declaring the follower/leader relationship as "tenuous" and "not very clear at times." Thus,

You can be the Department Chair, the Program Head, and to a certain extent, even the Dean, but you can't fire me! So is that person really a leader that has authority over what you do? [W]ith academic autonomy, there is very little control that they can have over what you do on a day-to-day basis when it comes to your teaching and your research, so it is very different from [other] organizational models.

Followers and leaders were conceptualized as working within the confines of "bureaucratic rules and regulations," which established parameters around their individual roles, decision-making abilities, degrees of agency, and their interactions with others. Interestingly, teachers saw themselves bringing intimate insider knowledge of the classroom and a deep commitment to their pedagogical approaches; whereas, leaders were characterized as having more awareness of institutional politics, national and international contexts, as well as administrative and resource constraints. Sometimes, these differences in knowledge, personal agendas, motivations, expectations, and beliefs became areas of contention. Followers report that even well-meaning and concerted efforts to locate "common ground" failed at times. Individual and collaborative efforts to engage in meaningful teaching and learning work were thwarted through incidents of ugly office politics, toxic 
gossip, and exclusion or isolation of people and ideas. Whenever leaders were perceived as using their hierarchical positions to intimidate, bully, exploit staff, and create difficult work environments, this often resulted in negative, even contagious, effects on followers and their work.

\section{DISCUSSION}

Our findings contribute to the fields of followership and leadership in three significant ways. Firstly, they illuminate the dynamic nature of the followership/leadership relationship in higher education, recognizing this relationship as reciprocal and clearly intersubjective, requiring that individuals demonstrate respect, patience, and openness throughout the processes of co-constructing positive relational spaces. Secondly, they suggest the complex and shifting roles of followers and leaders engaged in teaching and learning work, which must be acknowledged and balanced throughout their respective interactions with one another. There will be moments when followers need to be recognized as leaders, when leaders must assume a followership stance, and when changing contexts necessitate adaptability, a re-imagining and acceptance of alternative roles and visions. It is clear that the relationships between followers and leaders, as perceived by the former, directly influence how followers choose their responses and roles, even identities. Thirdly, the findings reflect some important ways to cultivate and sustain a healthy leadership/followership relationship in teaching and learning, namely through mutual understanding, a focus on commonalities rather than differences, bi-directional empathy, and ongoing consideration towards the complex needs of the followership. Leaders play a critical role in maintaining healthy (or damaging) interactions and practices in academic work environments, as these greatly impact followers' sense of agency, commitments to engaging in collaborative work, levels of confidence, sense of ownership, and abilities to develop into the best possible teachers who can maximize student learning. The positive and negative quality of follower-leader interactions can even impact followers and their teaching and learning work for several years afterwards, as seen in some vivid stories recounted by our participants.

The dynamic relational space cultivated by leaders and followers can be viewed as an extension of the follower-centric theoretical frameworks proposed by Carsten et al. (2010) and Uhl-Bien (2006) with an emphasis on co-construction. Our data indicate to the extent that leaders understand the need to engage in co-construction through mutual negotiation, their followers in higher education feel heard, feel respected, and are more willing in turn to reciprocate in positive ways. In an organization where the relational space between leaders and followers is actively constructive, each party learns from the other, followers can contribute more focused, on the ground, in-depth knowledge, while leaders can share broader, higher-level, knowledge. This may lead to better work cultures and, indirectly, more productive and effective teaching and learning (Ramsden et al., 2007). Similarly, an active rather than passive followership can open up possibilities for improving academic working and learning cultures for both faculty and students. Ultimately, academic "followers" are also leaders of their own students and peers. Their experiences with formally appointed leaders influences their own effectiveness in facilitating mutually respectful relationships and has the potential to help form more integrated, holistic higher education environments. 


\section{REASONS FOR NOT PARTICIPATING}

One aspect that may be significant for the study of academic followership lies in the reasons that a number of potential participants gave for not participating in the study. We believe their responses provide further insight into the follower/leader dynamic. We had each adopted different recruitment strategies (e.g., mass email, personalized email, telephone, and anonymous survey), consistent with the requirements at our individual institutions and sensitive to minimizing coercion or power relationships between researchers and prospective participants. Despite our comprehensive efforts to connect with individuals of interest, recruitment proved surprisingly difficult. Over 620 people received (or viewed) formal invitations to participate, yet only 38 individuals finally provided us with their narratives. Interestingly, we heard back from at least 20 individuals who had opted not to take part in our study. Their reasons shed further light on the complexities of followership/leadership dynamics and delineate future research directions.

Some people explicitly resisted identifying themselves as followers, preferring to regard themselves only as leaders. It seems that, despite the fact that most individuals become followers at one time or another in their academic careers, the label of follower holds particularly negative or uncomfortable connotations for teachers in higher education, as the research above has acknowledged (e.g., Bligh, 2011). In addition, the narratives suggest that there may be important gendered differences in the ways that teachers understand and experience followership and leadership, warranting further investigation. We also suspect that some people who do not hold formal leadership titles are widely perceived as leaders in higher education. Narratives recounting informal academic leadership in teaching and learning could help unravel these issues.

A few of the academics we heard from considered themselves to be neither followers nor leaders. They envisioned alternative roles or positionings for themselves as they engaged in pedagogic activities. Some cited minimal encounters with formal leaders, particularly in relation to matters of teaching and learning, while others could not recall any specific encounters thought to be worth sharing. On the other hand, there were responses proclaiming that "there is no leadership here," or straightforward remarks indicating "we just talk and decide." Perhaps these sentiments suggest that leadership sometimes goes on unnoticed. Additionally, a few individuals felt uncomfortable recounting experiences that reflected on someone else's behavior. One person saw this as "ratting on" the leader. Finally, many individuals expressed an interest in our study, but other commitments prevented them from volunteering. We intend to follow up with these individuals at a later date.

\section{CONCLUSION}

Our international study has examined how academic followers perceive and make sense of their roles and relationships with academic leaders and the way in which these issues may affect their teaching. While the study focused on relationships with formal leaders, there is obvious scope for research into followers' experiences of informal leadership.

The research has raised more questions than it answers, and the emergent themes point us towards further significant avenues to pursue. In particular, we need to tease out the effect that different institutional contexts - including national contexts - may have on followership, for, as Carsten et al. (2010) have observed, followers' behaviors are context-dependent. Further, the metaphors participants provided suggest a poten- 
tially fruitful analysis of the language used to describe followership experiences. The ways the narratives have framed followers' responses give us a window into their social constructions of the followership/leadership dynamic. In addition, an investigation into how power surfaces in the narratives would add important aspects to the leadership discourse in higher education.

This paper has sought to extend the literature on the scholarship of leadership in teaching and learning, through the lens of followership rather than leadership. This pathway has identified the complexity of the followership/leadership relationship. We have highlighted followership as a continuum from acquiescence to co-construction, identified the existence of both positive and negative relational spaces, and suggested their significance for teaching and learning. This international study contributes to an examination of "the construct of followership" in teaching and learning as a way of "advancing an 'expanded' view of leadership" (Carsten et al., 2010, p. 543). It also suggests that, in challenging times, academic leaders must attend to the characteristics and needs of their followerships.

Jennie Billot, PhD, is the Postgraduate Research Education Leader at AUT University, Auckland, New Zealand.

Deborah West is the Director of the Office of Learning and Teaching at Charles Darwin University in the Northern Territory, Australia.

Lana Khong is a Lecturer in the Policy and Leadership Studies Academic Group at the National Institute of Education, Singapore.

Christina Skorobohacz is a PhD candidate in the Faculty of Education at Brock University, Ontario, Canada.

Torgny Roxå is an Academic Developer at Lund University, Sweden, and ISSOTL Vice President for European Countries.

Shannon Murray is a Professor and 3M National Teaching Fellow in the Department of English at University of Prince Edward Island, Canada.

Barbara Mae Gayle, PhD, is the Vice President for Academic Affairs and Dean of Graduate Studies at Viterbo University, USA.

\section{REFERENCES}

Åkerlind, G., \& Kayrooz, C. (2003). Understanding academic freedom: The views of social scientists. Higher Education Research \& Development: Journal of the Higher Education Research and Development Society of Australia, 22(3), 327-344.

Allan, E. J., Gordon, S. P., \& Iverson, S. V. (2006). Re/thinking practices of power: The discursive framing of leadership in the Chronicle of Higher Education. The Review of Higher Education: The Journal of the Association for the Study of Higher Education, 30(1), 41-68.

Alvesson, M., \& Spicer, A. (2011). Metaphors we lead by. London: Routledge.

Berger, P., \& Luckmann, T. (1966). The social construction of reality: A treatise in the sociology of knowledge. Garden City, NY: Doubleday. 
Berlin, I. (2000). Two concepts of liberty. In H. Hardy \& R. Hausheer (Eds.), The proper study of mankind: An anthology of essays (pp. 191-242). New York: Farrat, Straus and Giroux.

Biggs, J., \& Tang, C. (2007). Teaching for quality learning at university. Maidenhead, England: The Society for Research into Higher Education.

Billot, J., \& Codling, A. (2013). Identifying the tensions of implementing research strategies: Implications for organizational leaders. Management in Education: The Journal of Professional Practice, 27(2), 75-80.

Bjugstad, K., Thach, E., Thompson, K., \& Morris, A. (2006). A fresh look at followership: A model for matching followership and leadership styles. Journal of Behavioral \& Applied Management, 7, 304-319.

Bligh, M. (2011). Followership and follower-centred approaches. In A. Bryman, D. Collinson, K. Grint, B. Jackson, \& M. Uhl-Bien (Eds.). The Sage handbook of leadership (pp. 425-436). Los Angeles: Sage Publications.

Carsten, M. K., Uhl-Bien, M., West, B. J., Patera, J. L., \& McGregor, R. (2010). Exploring social constructions of followership: A qualitative study. The Leadership Quarterly, 21, 543-562.

Cohen, L., Manion, L., \& Morrison, K. (2011). Research methods in education (7th ed.). London: Routledge.

Cousin, G. (2009). Researching learning in higher education: An introduction to contemporary methods and approaches. New York: Routledge.

Cox, R. W., Plagens, G. K., \& Sylla, K. (2010). The leadership-followership dynamic: Making the choice to follow. International Journal of Interdisciplinary Social Sciences, 5(8), 37-51.

Denzin, N., \& Lincoln, Y. S. (2003). The landscape of qualitative research: Theories and issues $\left(2^{\text {nd }}\right.$ ed.). Thousand Oaks, CA: Sage Publications.

Gibbs, G., Knapper, C., \& Picinnin, S. (2009). Departmental leadership for quality teaching -an international comparative study of effective practice. London: Leadership Foundation for Higher Education.

Giddens, A. (2004). The constitution of society. Cambridge: Polity Press.

Gosling, J., Bolden, R., \& Petrov, G. (2009). Distributed leadership in higher education: What does it accomplish? Leadership, 5(3), 299-310.

Jones, S., Lefoe, G., Harvey, M., \& Ryland, K. (2012). Distributed leadership: A collaborative framework for academics, executives and professionals in higher education. Journal of Higher Education Policy and Management, 34(1), 67-78.

Kean, S., \& Haycock-Stuart, E. (2011). Understanding the relationship between followers and leaders. Nursing Management, 18, 31-35.

Kezar, A., \& Lester, J. (2011). Enhancing campus capacity for leadership: An examination of grassroots leaders in higher education. Stanford, CA: Stanford University Press.

Marshall, S. J., Orrell, J., Cameron, A., Bosanquet, A., \& Thomas, S. (2011). Leading and managing learning and teaching in higher education. Higher Education Research \& Development: Journal of the Higher Education Research and Development Society of Australasia, 30(2), 87-103.

Martin, E., Trigwell, K., Prosser, M., \& Ramsden, P. (2003). Variation in the experience of leadership of teaching in higher education. Studies in Higher Education, 28(3), 247-259. 
Ramsden, P., Prosser, M., Trigwell, K., \& Martin, E. (2007). University teachers' experiences of academic leadership and their approaches to teaching. Learning and Instruction, 17, $140-155$.

Roxå, T., \& Mårtensson, K. (in press). How leaders can influence higher education cultures. Perspectives on Pedagogy and Practice.

Trevelyan, R. (2001). The paradox of autonomy: A case of academic research scientists. Human Relations, 54(4), 495-525.

Uhl-Bien, M. (2006). Relational leadership theory: Exploring the social processes of leadership and organizing. The Leadership Quarterly: An International Journal of Political, Social and Behavioral Science, 17(6), 654-676.

Weaver, L., Pifer, M. J., \& Colbeck, C. L. (2009). Janusian leadership: Two profiles of power in a community of practice. Innovative Higher Education, 34, 307-320.

Webster, L., \& Mertova, P. (2007). Using narrative inquiry as a research method: An introduction to using critical event narrative analysis in research on learning and teaching. London: Routledge. 